\title{
A STUDY TO ASSESS THE EATING ATTITUDE AMONG THE ADOLESCENT GIRLS OF 1ST YEAR B.Sc. NURSING BHUBANESWAR, ODISHA.
}

\begin{abstract}
Sahoo Sailabala ${ }^{1}$, DaleiSweta Rani ${ }^{2}$
${ }^{1}$ MSc Tutor, Department of Paediatric Nursing, Kalinga Institute of Nursing Science, KIIT Deemed to be University, Bhubaneswar, Odisha. E-mail: sailabalasahoo198@gmail.com

${ }^{2}$ MSc Tutor, Department of Pediatric Nursing, Kalinga Institute of Nursing Science, KIIT Deemed to be University, Bhubaneswar, Odisha. E-mail: swetaranidalei1993@gmail.com.
\end{abstract}

DOI: $10.29322 / I J S R P .10 .02 .2020 . p 9810$

http://dx.doi.org/10.29322/IJSRP.10.02.2020.p9810

\section{Research Type: Abstract}

Back ground: Eating disorders are more common in women; especially adolescent girls are at risks because they are preoccupied with their body shape, weight and diet. This study aims at majoring the eating attitudes of adolescent girls (19->22yrs) of $1^{\text {st }}$ yr B.Sc. Nursing, KINS, KIIT, Bhubaneswar. The positive and negative attitudes among adolescent girls on eating attitudes need special nutritional counselling. The objectives of the study were to assess the eating attitude among the adolescent girls and to find out associations between eating attitude with selected demographic variables.

Materials and methods: Non-experimental research approach and descriptive design was adopted for this study. Purposive sampling technique was used to collect data by using EAT-26 SCALE among the 50 B.SC Nursing $1^{\text {st }}$ year students.

Result: The study findings revealed that, majority (50\%) adolescent girls are coming under 19yrs (92\%) belongs to Hindu religion, $(100 \%)$ were $12^{\text {th }}$ pass, $(38 \%)$ were taking the previous source of information from books and journals, $(88 \%)$ are from nuclear family and $(68 \%)$ belongs to medium socio economic background. In this study $40 \%$ adolescent girls represent above 20 scores and $60 \%$ adolescent girls represents below 20 scores according to EAT-26 SCALE. Almost half of the students surveyed showed that, BMI $<18.5 \mathrm{Kg} / \mathrm{m}^{2}$ $(42 \%)$ were unaware of caloric value of food and dissatisfied with their appearance as compared to BMI 18.5$25 \mathrm{Kg} / \mathrm{m}^{2}(58 \%)$. Chi-square statistics was used, there was no association between eating attitude and selected demographic variables of adolescent girls.

Conclusions: The study highlights a need for counselling of adolescent girls in order to accept a healthy lifestyle.

Key words- Adolescent girls, eating disorders, eating attitude. 